\title{
Appropriate use: Neither restrictive nor a guideline
}

\author{
T. Brett Reece, MD
}

From the Division of Cardiothoracic Surgery, University of Colorado, Aurora, Colo.

Received for publication Oct 20, 2017; accepted for publication Oct 20, 2017; available ahead of print Nov 29, 2017.

Address for reprints: T. Brett Reece, MD, 12631 E 17th Ave, Room 6100, MS C310, Aurora, CO 80045 (E-mail: brett.reece@ucdenver.edu).

J Thorac Cardiovasc Surg 2019;157:572

$0022-5223 / \$ 36.00$

Copyright (c) 2017 by The American Association for Thoracic Surgery

https://doi.org/10.1016/j.jtcvs.2017.10.129

As a member of the rating panel representing The American Association for Thoracic Surgery (AATS), I learned a tremendous amount about the process that culminated in the document, "ACC/AATS/AHA/ASE/ASNC/HRS/ SCAI/SCCT/SCMR/STS 2017 Appropriate Use Criteria for Multimodality Imaging in Valvular Heart Disease." The American College of Cardiology (ACC) spearheaded this initiative, which was based on a task force within the organization. The impetus behind the document was an attempt to understand how to incorporate new and established imaging techniques optimally and cost-effectively into daily clinical care. The task force used a writing group that came up with a comprehensive list of scenarios and imaging techniques related to valvular heart disease. Once the scenarios had been refined, a rating panel inclusive of all subdisciplines dealing with valvular pathology was convened. The panel included the spectrum of imaging subspecialties, general cardiology, interventional cardiology, and cardiothoracic surgery. The rating panel discussed each scenario and the value of imaging modalities with respect to medical and interventional therapies.

The breadth of knowledge and the approaches discussed were significant. Although there was some campaigning regarding the roles of different modalities specific to valvular pathologies, the intent of the document was not to rate these modalities relative to one another. Rather, it was to suggest that the utility of each modality fell within the 3 broad categories of appropriate, may be appropriate, or rarely appropriate. In fact, the wording of these categories was kept vague specifically to avoid excluding any approaches altogether, because they may be the only modality available at certain facilities. The discussions included cutting-edge approaches, as well as approaches that have been established for many years. Most discussions revolved around the education of those on the panel regarding the modalities unfamiliar to their practices. There was little contention about the rankings, as evidenced by the generally tight scoring of most of the scenarios. As we moved through the process, the task force explained the intent of scenarios so that we might apply our opinions not only to

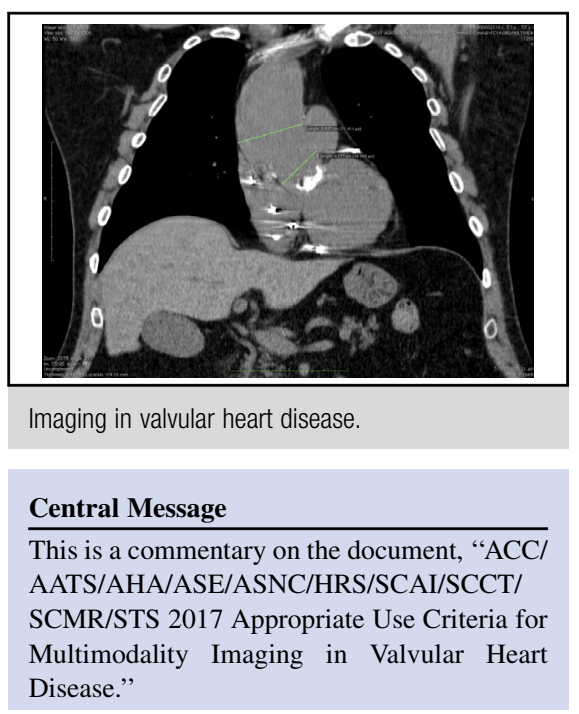

the imaging but also to the clarity of the scenario itself. It was easy to see the feedback was taken seriously, as scenario wording was revised to help the panel, and ultimately the reader of the document, elucidate the what the writing group was addressing. The multidisciplinary nature of the project was maintained throughout, with all interests being considered.

Entering into the process, the development of multidisciplinary documents can be very contentious among divergent interests. The development of this document avoided these disagreements, with all parties having equal voice. The ACC task force did a tremendous job putting the document together in a proactive move to help elucidate how imaging for valvular heart disease may best be used in current practice on the basis of the existing guidelines.

\section{Conflict of Interest Statement}

Author has nothing to disclose with regard to commercial support.

\section{Reference}

1. Doherty JU, Kort S, Mehran R, Schoenhagen P, Soman P. ACC/AATS/AHA/ASE/ ASNC/HRS/SCAI/SCCT/SCMR/STS 2017 appropriate use criteria for multimodality imaging in valvular heart disease: a report of the American College of Cardiology Appropriate Use Criteria Task Force, American Association for Thoracic Surgery, American Heart Association, American Society of Echocardiography, American Society of Nuclear Cardiology, Heart Rhythm Society, Society for Cardiovascular Angiography and Interventions, Society of Cardiovascular Computed Tomography, Society for Cardiovascular Magnetic Resonance, and Society of Thoracic Surgeons. J Am Coll Cardiol. 2017;70:1647-72. 